\title{
Towards joint consideration of adaptive capacity and water security: Lessons from the arid Americas
}

Christine J. Kirchhoff ${ }^{1}$, Francisco Lara-Valencia ${ }^{2}$, Julie Brugger ${ }^{3}$, Paula Mussetta ${ }^{4}$, Nicolás

Pineda-Pablos 5

\begin{abstract}
Freshwater resources face enormous pressures to meet human and ecosystem needs in a changing climate. These pressures brought concern for rising water insecurity high on global agendas and, renewed interest in improving water security. This review traces the recent evolution of these efforts including the challenges faced in attempts to enhance water security. In addition, this paper adds a new dimension to water security by proposing a theoretical model that jointly considers interdependencies between water security, adaptive capacity, and adaptive water management. Finally, the review illustrates and critically evaluates these interdependencies using three case studies from the US, Mexico and Argentina, and ends with suggestions for future research.

\footnotetext{
Addresses

${ }^{1}$ Department of Civil \& Environmental Engineering, University of Connecticut, 261 Glenbrook Road, Unit 3037

Storrs, CT 06269-3037, USA

${ }^{2}$ School of Transborder Studies, Julie Ann Wrigley Global Institute of Sustainability, Arizona State University, PO Box 875302, Tempe, AZ 85287-5302, USA

${ }^{3}$ Institute of the Environment, University of Arizona, ENR2 Building, 1064 E. Lowell Street, Room N582, PO Box 210137, Tucson, AZ 85721-0137, USA

${ }^{4}$ Instituto de Ciencias Humanas, Sociales y Ambientales, INCIHUSA - CCT CONICET Mendoza, Mendoza, Argentina

${ }^{5}$ El Colegio de Sonora, Avenida Obregón \#54 Col. Centro, C.P. 83000, Hermosillo, Sonora, México
}

Corresponding author: Christine J. Kirchhoff (christine.kirchhoff@uconn.edu)

\section{Introduction}

Human population and economic growth and land use change place enormous pressure on global freshwater resources [1]. Climate change exacerbates those pressures by altering water availability and precipitation patterns, increasing water demands, and worsening climate extremes (in particular, floods and droughts) [2]. The concept of water security-defined as the "sustainable availability of adequate quantities and qualities of water for resilient societies and ecosystems" [ $3 * *$, p. 281] emerged from this increasingly complex social and biophysical context, providing both an aspirational and a practical means to assess a range of water related risks and adaptations and to foster a more water secure world [see 4-6 for excellent reviews of the evolution of water security as a concept and see 6 for a review of the evolution of water security indicators]. More recently, adaptive management-defined as the science-based, iterative, learning oriented approach to plan for and respond to societal, ecosystem, and hydroclimatic uncertainties and to assess water security - has been promoted as the means to achieve water security [ $\left.3^{* *}, 7^{*}\right]$. However, to date, relatively little attention has been paid to assessing the underlying social conditions, capacities, and institutional flexibility necessary to support more adaptive approaches and build water security, a gap which this review addresses. In this paper, we review water security and adaptive capacity literatures and propose a conceptual model that links these concepts. We then briefly test the model exploring how adaptive capacity and adaptive water management supports (or not) improved water security using three examples 
from the US, Mexico and Argentina, and provide conclusions and suggestions for future research.

\section{Water Security and Adaptive Capacity}

The concept of water security evolved from a relatively narrow framing focused on resource geopolitics, in the Middle East and arid regions of Africa [8], to increasingly broader framings, inclusive of water quantity and quality, the needs of both humans and ecosystems [9], and, more recently, uncertainty and sustainability $\left[3^{* *}, 7 *\right]$ resulting from climate change. Correspondingly, indicators of water security, once narrowly focused on physical water (in)security (too much or too little water)[10], broadened to include other measures such as the availability of water for human and ecosystem health and, more recently, social and governance indicators [11-13]. For a comprehensive review of the conceptual evolution of water security and of water security indicators see 4,6,12,14]. Taken together, this broadened approach to water security begins to account for and overcome trade-offs [14-16], where increases in one aspect of water security may diminish another, and to facilitate adaptation to increasing climate and hydrologic variability $\left[7^{*}, 17,18^{*}\right]$.

While these changes in framing and assessing water security represent significant conceptual advancements that could engender comprehensive water security under greater climate and hydrologic uncertainty, challenges remain in achieving comprehensive water security in practice. Difficulties arise for two reasons. First, research suggests that achieving water security depends on implementing new, more flexible, change-oriented water management approaches such as adaptive water management that enable adjustment to changing conditions [ $\left.3 * *, 7 *, 18^{*}\right]$. Unfortunately, traditional, command and control-type water management approaches still dominate the water governance landscape impeding the more flexible, learning and change oriented management advocated by scholars for achieving water security. Second, and perhaps more importantly, research suggests that underlying adaptive capacities--capacities that facilitate learning, adapting to changes, and transforming management--are often inadequate to support transitions to more adaptive regimes $[15,19,20]$. That is, even if water managers wanted to transition from traditional to adaptive management, insufficient adaptive capacities--including inadequate resources (i.e., economic, technology, information and skills, infrastructure), institutions, and equity [21], insufficient capacity for collective action [22,23], or for learning and changing institutions, governance, and management regimes [19,24-28], or for transforming social ecological systems $[29,30 * *]$ - hamstring such efforts before they even get off the ground [31].

As the preceding discussion lays out, there appears to be a critical connection between adaptive capacity, transitions to more flexible, learning and change oriented water management approaches (hereafter adaptive water management), and water security. These connections are illustrated in a conceptual model--building blocks for enabling advancements in comprehensive water security (see Figure 1). The model shows how different types of adaptive capacities are required to build sufficient support to transition from conventional, top-down water management to adaptive water management. In turn, both adaptive capacities and adaptive water management are precursor building blocks to facilitate enhanced water security. As sufficient adaptive capacities and adaptive water management build up together these support improved, more 
comprehensive water security that takes into account physical water (in)security as well as tradeoffs, sustainability and social and governance aspects.

\section{Figure 1 about here.}

To explore the theorized interplay between adaptive capacity, adaptive water management, and water security in more depth, we employed a holistic, multiple-case study approach [32,33]. Selection of cases was purposive as we wished to explore potentially contrasting water security outcomes as we observed different levels of adaptive capacity and adaptive water management in three real-world contexts: Tucson, Arizona, Mendoza, Argentina, and in the Sonora River Basin, Mexico. While the cases differ in levels of adaptive capacity and adaptive water management, all three share the burden of being in a water constrained region of the world, the Arid Americas. As such, all three sites experience water-related crisis events, such as drought, which create motivation for improving water security and opportunities to assess how and why improvements in water security succeed or fail. Table 1 outlines the three cases in terms of the crisis event, level of adaptive capacity, and type of water management along with the scale at which the respective water management operates. A description of each case follows the table.

\section{Table 1 about here.}

\section{Enhancing Adaptive Capacity and Water Security in the Arid Southwest USA}

In the U.S. Southwest, for decades "hard path" or infrastructure-centric water resource management contributed to enhancing the region's water security supporting expansive growth in both agricultural production and urban populations [34]. But infrastructure-centric solutions are insufficient for achieving long-term water security as physical, economic, and ecological limits together with climate change constrain water supplies [34-37]. Tucson Water, a municipally owned and operated water utility that supplies drinking water to most of the one million inhabitants of the Tucson Metropolitan Area in the state of Arizona, sits at the epicenter of this water security challenge.

As a municipally-owned utility, Tucson Water operates under the direction of the City Council an arrangement which facilitates active citizen engagement in water management through the electoral and ballot initiative processes, but which can also create uncertainty in the system. For example, when Tucson Water introduced a higher water rate in 1976 to pay for infrastructure needed to meet rising water demands, citizens organized a recall election of the City Council members who voted for the increase. And when the utility tried to switch from groundwater to Colorado River water delivered by the Central Arizona Project (CAP) in 1992, citizens passed a ballot initiative that prevented direct delivery. Both of these citizen responses threatened water security in the short-term.

The 1976 crisis prompted the City Council to create an official public advisory body, the Tucson Citizens' Water Advisory Committee (CWAC), comprised of Tucson residents knowledgeable about water management, to advise them on water rates and capital improvement planning. The CWAC increased the transparency and legitimacy of the rate setting process which ultimately contributed to public acceptance of higher water rates [38]. In addition to advising on water rates, the CWAC suggested creating peak flow reduction and public education campaigns, which 
together contributed to Tucson's transformation from an "oasis," whose main streets, parks, and residences were landscaped with lawns and water-demanding trees, into a "desert city," landscaped with native and low-water use vegetation, and to the widespread adoption of conservation values [39]. The CWAC also played an important role in gaining public acceptance of the eventual solution to the 1992 impasse and the higher rates it entailed, which was to recharge the CAP water into the aquifer and then pump the blended water back out. Tucson is now able to bank one-half year of supply annually, reducing the risk of water shortage in the future. Over time, the CWAC has evolved to take on an advisory role in additional issues, such as conservation programs and a Water Service Area Policy. Meanwhile, water consumption rates have continued to drop and are now among the lowest in the nation for a large metropolitan area. ${ }^{1}$ Altogether, the CWAC has helped the utility to shift to "soft path" solutions including managing demand through alternative pricing structures, conservation incentives, water-saving technologies, alternative supplies, and educating users. By increasing the learning capacity and flexibility of the municipal water supply system, the CWAC has increased Tucson Water's capacity to adapt to changes in environmental, technical, regulatory, and social conditions [26], which enhances water security in the region.

\section{Trade-offs in Adaptive Capacity and Water Security Building in Mendoza, Argentina}

Mendoza, Argentina, a semiarid region located in the west-central part of the country, relies on snow and glacier melt water originating in the Andes mountain range. Water infrastructure and strong water institutions manage - from a supply-side model - the movement of water from its source in the Andes to its use for agriculture and other human needs. Given the aridity of the region, droughts are not uncommon. Climate change is likely to exacerbate water scarcity in the future [40] potentially compromising water security for those with less adaptive capacity.

Past droughts have prompted strengthening of institutions and adaptive capacity building including increasing the production of knowledge, participation in water decisions, and the adoption of new technologies. Unfortunately, these changes have not uniformly increased water security for all water users; rather, some users are more secure while other water users are left less secure. For example, while government institutions make water availability, climate, and agricultural adaptation information publically available, the information is highly technical and not easy to access for small farmers. As a result, while large agricultural producers' access and use this expert information and their adaptive capacity improves, smaller producers tend not to reap these adaptive capacity benefits. The case for participation is more mixed. On the one hand, while Irrigator Assemblies - ancient, formal, non-state, community organizations - provide space for discussion and participation in water decisions, unequal representation (some landowners have more votes while others have no vote at all) and a lack of capacity for taking action limits adaptive capacity. On the other hand, informal associative organizations for common use of water, technology and machinery contribute to the improvement of producers' adaptive capacity as agreements to share irrigation wells create possibilities that these producers could not engage in on their own. Finally, while adoption of water saving technologies such as drip irrigation or lining of irrigation canals do foster more efficient use of water that can help irrigators cope with water shortages, there are potential limits and trade-offs [41](Mussetta et al forthcoming). For example, while the Potrerillos Dam [41] assisted some irrigators by creating more stable, predictable water flows on the Mendoza River, other irrigators located further away

\footnotetext{
${ }^{1}$ Tucson Water presentation at CWAC meeting 04/01/2015.
} 
lost access to the water and became more water insecure. Moreover, over-reliance on technological fixes may actually limit adaptive capacity building through other means that are more appropriate for a given socio-historical or local context such as rural development based on agro-ecology practices [42*]. Even with these trade-offs, altering the prevailing "technology as savior" paradigm is not an easy task since they are embedded in current models of territorial development.

\section{The Sonora River Basin - Climate Challenges, Adaptation Urgencies}

The Sonora River stretches 294 kilometers, spanning from the Cananea's highlands near the U.SMexico border to the Gulf of California in the Pacific Ocean [43]. The City of Hermosillo, the main urban center and capital of the state of Sonora, depends increasingly on a single water source - groundwater - since surface water rarely reaches Rodriguez Dam, the main component of the water supply infrastructure in the lower river basin [44].

Water insecurity in the SRB is an area of great concern as growth and recurring drought, exacerbated by climate change, places enormous pressure on an intermittent freshwater supply and on a management system that relies on supply-side water strategies, the construction of hard infrastructure (i.e., hard path approaches), inter-basin water transfers, and centralized, top-down decision-making. The prolonged drought in the early 2000s and the spill of 40,000 cubic meters of toxic chemicals by a mining operation in the upper basin in 2014 [45,46], brought the risk of higher water insecurity into sharp focus. These events prompted calls for building adaptive capacity and for transitions to more adaptive, integrated water management, including multisectoral coordination, demand management, science-based long-term planning, and public involvement.

Efforts to build adaptive capacity to support more science-based, transparent and learningfocused management are slowly emerging in the region. For example, the Mexican Government recently commissioned studies to evaluate water management under climate change scenarios, recommending monitoring and modeling of hydro-climatic processes as well as greater transparency in water policy-making $[47,48]$. Another illustration is the formation of a regional epistemic community working across the US-Mexico border and advocating social learning, the creation of binational "communities of practice" among water managers, and the co-generation of climate science [44,48-49].

Despite some progress, adaptive capacity and water security gains have been unequal and tenuous across the SRB illustrating the difficulties of changing existing paradigms and achieving water security even when there is motivation to do so. For example, at the onset of the early 2000s drought, authorities quickly opened new wells and instituted water rationing. Unfortunately, these measures improved water security for Hermosillo but negatively impacted vulnerable populations in the peri-urban areas decreasing their water security and adaptive capacity and amplifying social inequities [49]. A similar result emerged from the recent construction of the Independence Aqueduct to transfer water from the neighboring Yaqui River to the SRB. The transfer improved water security for urban dwellers in Hermosillo but left farmers and indigenous peoples living in the Yaqui River Basin less secure and without a voice or power in the decision making process [50]. Other trade-offs are evident between the upper and lower SRB and between short- and long-term gains in water security. In this case, overextraction of groundwater as a strategy prioritizes short- over longer term water security [51] Finally, the government's handling of the massive release of toxic chemicals into the river in 
2014, making decisions behind closed doors 2000 kilometers away in Mexico City, lacked transparency and credibility among regional water users. These examples illustrate that even when stakeholders agree on the need to improve adaptive capacity and water security, overcoming entrenched water management and growth paradigms is difficult.

\section{Insights from Three Cases on the Interplay between Adaptive Capacity, Adaptive Water Management and Water Security}

Concerns for the adequacy of water supplies to support growth amidst recurring drought and the specter of climate change motivate efforts to build water security across the three cases. While motivation for building water security is high across the three cases, motivation alone is insufficient for achieving desired water security gains. Rather, the cases illustrate that adaptive capacity and adaptive water management play critical roles in supporting (or undermining) water security building efforts. For example, on the one hand, in Tucson citizen participation promotes social learning, and enhances transparency and legitimacy in water management increasing adaptive capacity. In turn, greater adaptive capacity supports the transition from traditional, hardpath, top-down water management to a more adaptive water management paradigm. Adaptive capacity supported adaptive water management enables ongoing adaptations including institutional, organizational, operational, and behavioral changes that embrace both hard- and soft-path solutions yielding gains in water security. On the other hand, despite high motivation for building water security in Mendoza and the SRB, unequal adaptive capacity (Mendoza) or low adaptive capacity (in SRB) are not enough to support transitioning away from entrenched top-down water management paradigms to more adaptive management approaches undermining water security building efforts. For example, in both Mendoza and the SRB, while past droughts have prompted adaptive capacity building including the production of knowledge to support water management decisions, water security gains are unequally distributed as not all water users can take advantage of the information. And, in both Mendoza and the SRB, traditional water management structures have been slow or reluctant to open their decision-making process to citizens and the scientific community which, in turn, has diminished the capacity for learning and participatory management hallmarks adaptive water management. In the case of the SRB, social unrest and political mobilization are gradually forcing change in water governance at municipal and regional levels; but, these changes are tenuous and easily side-stepped as illustrated by the government's response to the recent chemical spill and the construction of the Independence Aqueduct. And in Mendoza, even with formal participatory structures in place at the community scale, unequal representation and lack of power to act within the system, lead some farmers to take the initiative to create for themselves the best conditions for improving their own water security at the sub-community (e.g., multi-farm) scale. However, the extent to which gains in water security at sub-community scales are sustainable is an unanswered question given the potential for forces outside farmer collaboratives to counteract or undermine their water security gains.

While the Tucson, Mendoza and SRB cases broadly support the normative propositions of the conceptual model, the Mendoza and SRB cases illustrate challenges inherent in building adaptive capacities and transitioning to adaptive water management regimes and the need to attend to inequalities and trade-offs. For example, consistent with the scholarship in this area, the Mendoza and SRB cases illustrate the importance of considering who benefits (or loses) from adaptive capacity and water security building efforts especially among more or less advantaged 
populations $[49-50,52 *, 53]$. Vulnerable populations in particular tend to lose out when broader adaptive capacity building efforts do not take into account differences in accessibility or power. Finally, the SRB case illustrates the challenge with trade-offs, such as when building adaptive capacity for the short-term may trade-off capacities for longer term adaptation or enhancing water security in one location or for one purpose may reduce water security in another, are another challenge $\left[16,18^{*}, 19,54\right]$. For example, in the SRB case, groundwater over-extraction prioritizes short- over long-term water security or where water security improved in the SRB at the expense of the Yaqui River basin.

\section{Conclusions and Future research}

In this paper, we proposed a conceptual model showing the interplay between adaptive capacities required to build sufficient support to transition to adaptive water management and how both capacities and adaptive water management are necessary to support improvements in comprehensive water security. Insights drawn from the three case studies provide some support for this conceptual model. On the one hand, crises together with transformative adaptive capacity help reshape water management systems/paradigms and enhance water security. On the other hand, gains in comprehensive water security stall or become unequal when there is insufficient local adaptive capacity to support transitioning away from entrenched, traditional, top-down water management to adaptive water management. The cases also illustrate challenges in assembling those building blocks to advance the potential to achieve comprehensive water security. Local contexts and conditions influence the effectiveness (or lack thereof) of adaptive capacity building efforts and the difficulties of transitioning away from traditional water management regimes.

This review and our conceptual model highlight the critical role adaptive capacity plays in supporting adaptive management transitions and building water security. Our results suggest that water security indicators should account for the adaptive capacity and adaptive water management building blocks that support achieving comprehensive water security. Furthermore, since water security itself can be a moving target as environmental, technical, regulatory, and social conditions change, including indicators to assess adaptive capacity and adaptive water management provides a means to gauge capacity for building and sustaining water security over time.

While our review provides a foundation to advance thinking around the interplay between adaptive capacity, adaptive water management and water security, future scholarship should explore both the relative influence of different types of adaptive capacities on adaptive water management transitions and water security as well as how adaptive capacity building can be improved to minimize negative trade-offs. This focus could shed light on which capacities in particular are critical to build and measure in assessments of water security. Likewise, future research should examine in more depth what enables or constrains transforming water management paradigms in a wider range of contexts. This research could help uncover and link specific underlying capacities and factors that drive change in water management in different environments, critical for informing efforts to support transitions in entrenched water management paradigms and, ultimately, for building and measuring water security. 


\section{Acknowledgements}

We would like to thank the current and former CWAC members, Tucson Water staff, and the members of the Tucson City Council and their staff who gave their time to make the research in Tucson possible. This research was supported by the National Oceanic and Atmospheric Administration's Climate and Societal Interactions Program grant number NA11OAR4310143. Finally, this work was also partially supported by a grant from the Inter-American Institute for Global Change Research (IAI) CRN3056 which is supported by the US National Science Foundation (Grant GEO-1128040) and by the Lloyd's Register Foundation. 


\section{References and recommended reading}

1. Vorosmarty CJ, McIntyre PB, Gessner MO, Dudgeon D, Prusevich A, Green P, Glidden S, Bunn SE, Sullivan CA, Liermann CR, Davies PM: Global threats to human water security and river biodiversity. Nature 2010, 467: 555-561.

2. IPCC: Climate Change 2014: Impacts, Adaptation, and Vulnerability. Geneva, Switzerland: World Meteorological Organization; 2014.

3. **Scott CA, Meza FJ, Varady RG, Tiessen H, McEvoy J, Garfin GM, Wilder M, Farfán LM, Pablos NP, Montaña E: Water security and adaptive management in the arid Americas. Annals of the Association of American Geographers 2013, 103(2):1-9.

Expands conceptualization of water security to address societal-ecosystem-hydroclimatic interactions, dynamics and uncertainties and argues that adaptive management helps ensure water security.

4. Bakker K: Water Security: Research challenges and opportunities. Science 2012, 337: 914.

5. Cook C, Bakker K: Water security: Debating and emerging paradigm. Global Environmental Change 2012, 22: 94-102.

6. Garrick D, Hall JW: Water Security and Society: Risks, Metrics, and Pathways. Annual Review of Environment and Resources 2014, 39:611-639.

7. *Allan C, Xia J, Pahl-Wostl C: Climate change and water security: challenges for adaptive water management. Current Opinion in Environmental Sustainability 2013, 5:625-632.

Discusses the interrelationships between water security and adaptive management and demonstrates the utility of adaptive management for addressing water-food-energy security nexus.

8. Anderson EW: The political and strategic significance of water. Outlook on Agriculture 1992, 21: 247-253.

9. Grey D, Sadoff CW: Sink or Swim? Water security for growth and development. Water Policy 2007, 9:545-571.

10. Falkenmark M, Berntell A, Jagerskog A, Lundqvist J, Matz M, Tropp H: On the Verge of a New Water Scarcity: A Call for Good Governance and Human Ingenuity. Stockholm, Sweeden: Stockholm International Water Institute. 2014.

11. Araral E, Yu DJ: Comparative water law, policies, and administration in Asia: evidence from 17countries. Water Resour. Res. 2013, 49:5307-16. 
12. Plummer R, de Loë R, Armitage D: A systematic review of water vulnerability assessment tools. Water Resour. Manag. 2012, 26:4327-46.

13. Schulze S, Schmeier S: Governing environmental change in international river basins: the role of organizations. Int. J. River Basin Manag 2012, 10:229-44.

14. Bakker K, Morinville C: The governance dimensions of water security: a review. Philosophical Transactions of the Royal Society 2013, 371:20130116.

15. Norman ES, Dunn G, Bakker K, Allen DM, Cavalcanti de Albuquerque R: Water security assessment: Integrating governance and freshwater indicators. Water Resources Management 2013, 27:535-551.

16. Palmer MA: Beyond infrastructure. Nature 2010, 467: 534-535.

17. Briscoe J: Water security in a changing world. Daedalus 2015, 144(3): 27-34.

18. *Pahl-Wostl C, Palmer M, Richards K: Enhancing water security for the benefits of humans and nature - the role of governance. Current Opinion of Environmental Sustainability 2013, 5:676-684.

Critically assesses governance approaches and water security measures in terms of trade-offs between different water security dimensions and argues for both more attention and experimentation with governance modes to address those trade-offs.

19. Hill M, Engle NL: Adaptive Capacity: Tensions across Scales. Environmental Policy and Governance 2013, 23: 177-192.

20. Pahl-Wostl C, Craps M, Dewulf A, Mostert E, Tabara D, Taillieu T: Social Learning and Water Resources Management. Ecology and Society 2007, 12(2): 5.

21. Staber U, Sydow J: Organizational Adaptive Capacity A Structuration Perspective. Journal of Management Inquiry 2002, 11(4): 408-424.

22. Smit B, Pilifosova O: Adaptation to climate change in the context of sustainable development and equity. In Climate change 2001: Impacts, adaptation and vulnerability, Chapter 18. Cambridge: Cambridge University Press: 2001.

23. Adger WN: Social Capital, Collective Action, and Adaptation to Climate Change. Economic Geography 2003, 79(4):387-404.

24. Pelling M, High C: Understanding adaptation: What can social capital offer assessments of adaptive capacity? Global Environmental Change 2005, 15(4):308-319.

25. Brown K, Westaway E: Agency, Capacity, and Resilience to Environmental Change: Lessons from Human Development, Well-Being, and Disasters. Annual Review of Environment and Resources 2011, 36: 321-342. 
26. Eakin H, Lemos MC: Adaptation and the state: Latin America and The challenge of capacity-building under globalization. Global Environmental Change 2006, 16(1): 7-18.

27. Engle NL, Lemos MC: Unpacking governance: Building adaptive capacity to climate change of river basins in Brazil. Global Environmental Change-Human and Policy Dimensions 2010, 20(1): 4-13. doi: 10.1016/j.gloenvcha.2009.07.001.

28. Gupta J, Termeer C, Klostermann J, Meijerink S, van den Brink M, Jong P, Nooteboom S, Bergsma E: The Adaptive Capacity Wheel: a method to assess the inherent characteristics of institutions to enable the adaptive capacity of society. Environmental Science \& Policy 2010, 13(6):459 - 471. doi: DOI: 10.1016/j.envsci.2010.05.006

29. Lemos MC, Agrawal A, Eakin H, Nelson DR, Engle NL, Johns O: Building adaptive capacity to climate change in less developed countries: Climate science for serving society. Netherlands: Springer; 2013: 437-457.

30. **Pelling M, O’Brien K, Matyas D: Adaptation and transformation. Climatic Change 2015, 133: 113-127.

Expands understanding of transformation as an adaptive response to climate change by providing a framework that captures the diverse components of coevolving social-ecological systems and helps identify the spaces and relationships in which transformation can be observed and transmitted.

31. Medema W, McIntosh BS, Jeffrey PJ: From premise to practice: a critical assessment of integrated water resources management and adaptive management approaches in the water sector. Ecology and Society 2008, 13(2): 29.

32. Yin RK. Applications in case study research. Thousand Oaks, California: SAGE; 2012.

33. Yin RK. Case study research: Design and methods. Thousand Oaks, California: SAGE; 2013.

34. Zeitoun M: The global web of national water security. Global Policy 2011, 2(3): 286-296.

35. Gleick, PH: Roadmap for sustainable water resources in southwestern North America. Proceedings of the National Academy of Sciences 2010, 107(50): 21300-21305.

36. Cayan D, Tyree M, Castro KEKC, Gershunov A, Barsugli J, Ray AJ, Overpeck J, Anderson M, Russell J, Rajagopalan B, Rangwala I, Duffy P: Future Climate: Projected Average. In Assessment of Climate Change in the Southwest United States: A Report Prepared for the National Climate Assessment. Edited by Garfin G, Jardine A, Merideth R, Black M, LeRoy S. Washington, DC: Island Press; 2013: 101-125.

37. Gershunov A, Rajagopalan B, Overpeck J, Guirguis K, Cayan D,Hughes M, Dettinger M, Castro C, Schwartz RE, Anderson M, Ray AJ, Barsugli J, Cavazos T, Alexander M: Future 
Climate: Projected Extremes. In Assessment of Climate Change in the Southwest United States: A Report Prepared for the National Climate Assessment. Edited by Garfin G, Jardine A, Merideth R, Black M, LeRoy S. Washington, DC: Island Press; 2013: 126-147.

38. Udall B: Water: Impacts, Risks, and Adaptation. In Assessment of Climate Change in the Southwest United States: A Report Prepared for the National Climate Assessment. Edited by Garfin G, Jardine A, Merideth R, Black M, LeRoy S. Washington, DC: Island Press; 2013: 197-217.

39. Martin WE, Ingram HM, Laney NK, Griffin AH: Saving Water in a Desert City. Washington, D.C.: Resources for the Future; 1984.

40. McPherson EG, Haip RA: Emerging Desert Landscape in Tucson. Geographical Review 1989, 79(4): 435-449.

41. Montaña Elma and José Armando Boninsegna: Drought in the Oasis of Central Western Argentina. In Vulnerability and Adaptation to Drought: The Canadian Prairies and South America. Edited by Diaz H, Hurlbert M, Warren J. Calgary: University of Calgary Press; (in press).

42. *Mussetta et al.: forthcoming. Vulnerability to climate extreme events: Difficulties in using indicators in two basins of Argentina and Colombia.

The paper makes an important contribution in assessing both methodological and theoretical difficulties in building indicator to assess vulnerability to climate variability and extreme events and demonstrates their weaknesses to account for complex phenomena.

43. Montaña Elma: Escenarios de Cambio Ambiental Global, Escenarios de Pobreza Rural: Una Mirada desde el Territorio. Buenos Aires, Argentina: CLACSO; 2013: 336 p.

44. Wilder M, Scott CA, Pablos NP, Varady RG, Garfin GM, McEvoy J: Adapting Across Boundaries: Climate Change, Social Learning, and Resilience in the U.S.-Mexico Border Region. Annals of the Association of American Geographers 2010, 100: 917-928.

45. México: Remediación Ambiental Río Sonora. 10. Gobierno de la Republica de México.

46. Reyes A, Quintero ML: Problemática del agua en los distritos de riego por bombeo del estado de Sonora. Revista Digital Universitaria 2009, 10(6):1-19.

47. CONAGUA: Programa detallado de acciones de gestión integral para la restauración hidrológica del Río Sonora. Ciudad de México: Comisión Nacional del Agua/Secretaría del Medio Ambiente y Recursos Naturales; 2013.

48. CONAGUA: Estudios de investigación para caracterizar a las regiones del país en función del cambio climático, incluyendo los mapas asociados: II Noroeste. Ciudad de México: Comisión Nacional del Agua/Secretaría del Medio Ambiente y Recursos Naturales; 2012. 
49. Eakin H, Magaña V, Smith J, Moreno J, Martínez J, Landavazo O: A stakeholder driven process to reduce vulnerability to climate change in Hermosillo, Sonora, Mexico. Mitigation and Adaptation Strategies for Global Change 2007, 12: 935-955.

50. Moreno-Vázquez JL: Despojo de agua en la Cuenca del río Yaqui. Hermosillo: El Colegio de Sonora, 2014.

51. Moreno JL: “A Never-Ending Source of Water": Agriculture, Society, and Aquifer Depletion on the Coast of Hermosillo, Sonora. Journal of the Southwest 2012, 54: 545568.

52. *Wilson S, Pearson LJ, Kashima Y, Lusher D, Pearson P: Separating Adaptive Maintenance (Resilience) and Transformative Capacity of Social-Ecological Systems. Ecology and Society 2013, 18(2): 22.

Considers whether characteristics of social-ecological systems necessary for transformation may be distinct from those necessary for adaptive maintenance or resilience and proposes metrics that may be used to assess these two types of system changes.

53. Dow K, Kasperson RE, Bohn M: Exploring the Social Justice Implications of Adaptation. In Fairness and Climate Change. Edited by Adger WN et al. Cambridge, MA: MIT Press; 2006: 79-96.

54. Vazquez de Leon M: Hispanic Farmers and Farmworkers: Social Networks, Institutional Exclusion, and Climate Vulnerability in Southeastern Arizona. American Anthropologist 2009, 111 (3):289-301. 


\section{Figure and Table Captions}

Figure 1. Theorized interdependencies between water security, adaptive capacity and adaptive management. From the left, the model shows how different types of adaptive capacities are required to support transitioning from conventional water management to adaptive water management. Proceeding from left to right, the figure shows how both adaptive capacities and adaptive water management must build together to support improved, more comprehensive water security.

Table 1. Multi-case study design breakdown of case selection with crisis event and amounts of adaptive capacity and adaptive management. 


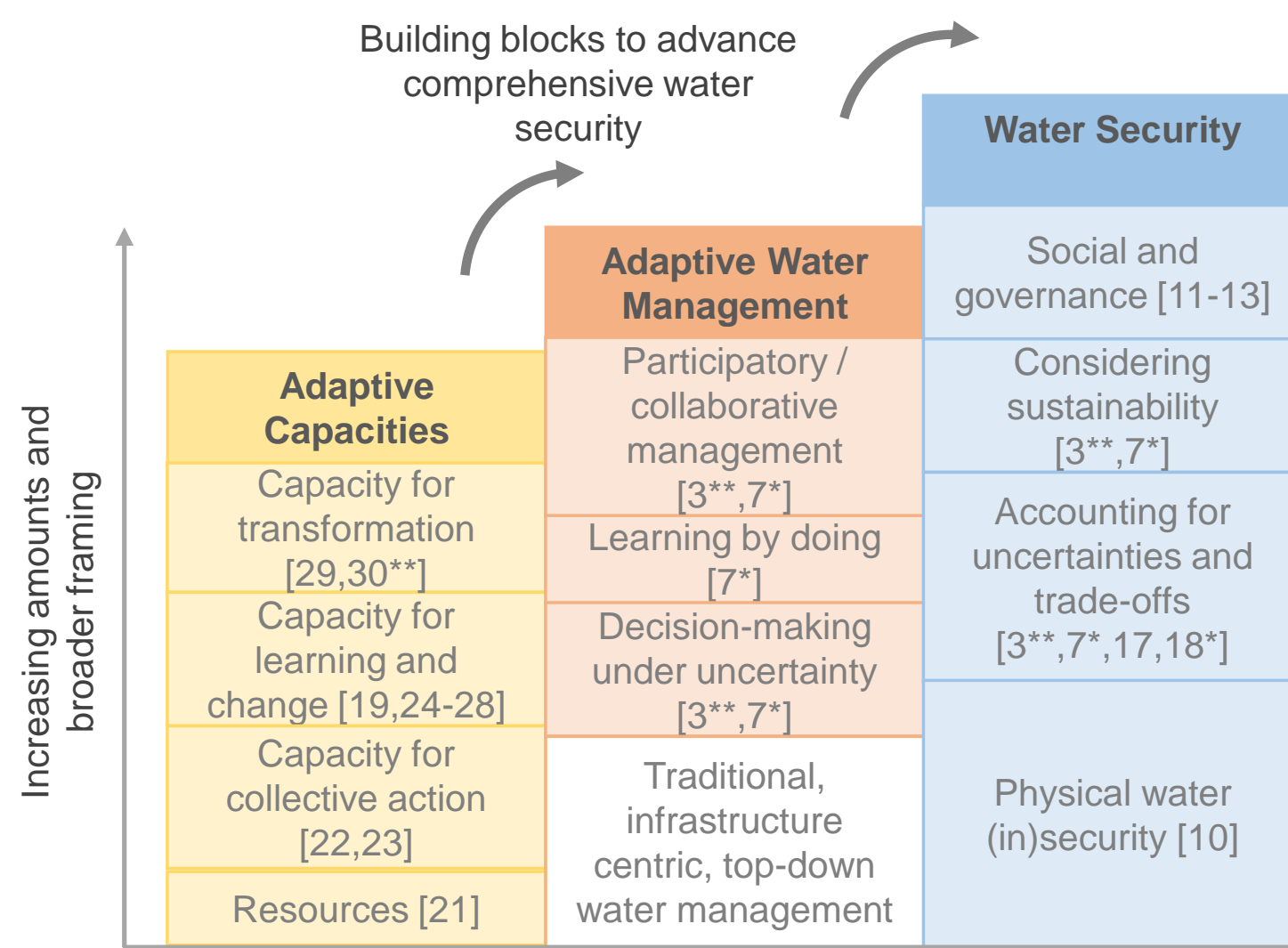

Advancing the potential for and likelihood of achieving comprehensive water security 


\begin{tabular}{llll}
\hline Case & \multicolumn{1}{c}{ Crisis } & Levels of Adaptive Capacity & $\begin{array}{l}\text { Type of Water Management } \\
\text { (Scale) }\end{array}$ \\
\hline Tucson, Arizona, USA & Water supply transition & High & Adaptive (city) \\
Mendoza, Argentina & Drought & Unequal & Not fully adaptive (community) \\
& & - High, rich farmers & \\
& & - Medium or low, poor farmers & \\
Sonora, Mexico & $\begin{array}{l}\text { Drought, toxic chemical } \\
\text { spill }\end{array}$ & Low & Traditional (national) \\
\hline
\end{tabular}

